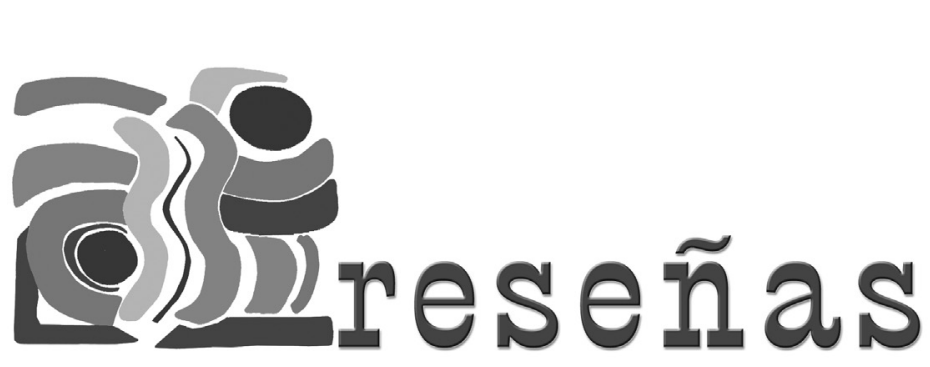

\title{
El estado oculto de la salud
}

(Hans-Georg Gadamer. Barcelona: Gedisa; 2001)

\section{La práctica médica en la era de la tecnología}

(Karl Jaspers. Barcelona: Gedisa; 2003)

\section{Por: María Inés Jara-Navarro*}

\section{doi:10.11144/Javeriana.rgyps15-31.eods}

\section{Como citar esta reseña:}

Jara-Navarro MI. El estado oculto de la salud. Reseña del libro La práctica médica en la era de la tecnología Karl Jaspers. Barcelona: Gedisa; 2003. Rev. Gerenc. Polít. Salud. 2016; 15(31): 323-325. http://dx.doi.org/10.11144/Javeriana.rgyps15-31.eods

Dada la importancia que tienen la salud, la salud pública y la administración de la salud, en esta ocasión se presenta de breve manera la reseña de dos libros que a mi juicio constituyen una interesante reflexión filosófica de la salud y de esta en la era tecnológica.

\section{El estado oculto de la salud}

Gadamer, a partir de las conferencias que impartió a los médicos, construye el texto titulado El estado oculto de la salud, el cual presenta diversas perspectivas hermenéuticas sobre la vida. Para el autor, la salud es una extraña y oculta realidad que solo se percibe cuando se ha perdido. En La República Platón compara la salud con la rectitud del ciudadano que concibe la comunidad como armonía, concordancia de opuestos complementarios. Gadamer añade, ejemplificando con un "tronzador": uno tira de un extremo de la sierra y quien está en el otro lado se deja arrastrar; este vaivén genera un círculo para que el movimiento tome un ritmo: si una fuerza aumenta o disminuye, arruina el trabajo. El ritmo hace suponer falta de esfuerzo (1). La salud es, pues, "el ritmo de la vida, un proceso continuo en el cual el equilibrio se estabiliza una y otra vez". La resistencia es desequilibrio, opera como la ingravidez

\footnotetext{
Filósofa, licenciada en Ciencias Sociales, con dos maestrías, una en Investigación y Tecnología Educativa y otra en Filosofía. Diplomada en Gestión de Proyectos en Políticas Públicas, docente de los Programas de Posgrados en Administración de Salud y Seguridad Social y del Instituto de Salud Pública de la Pontificia Universidad Javeriana, Bogotá, Colombia. Miembro del Grupo de Filosofía del Dolor de la Facultad de Filosofía de la Pontificia Universidad Javeriana. Directora de la Revista Gerencia y Políticas de Salud, editora de la Colección de Libros Gerencia y Politicas de Salud. Correo electrónico mjara@javeriana.edu.co
}
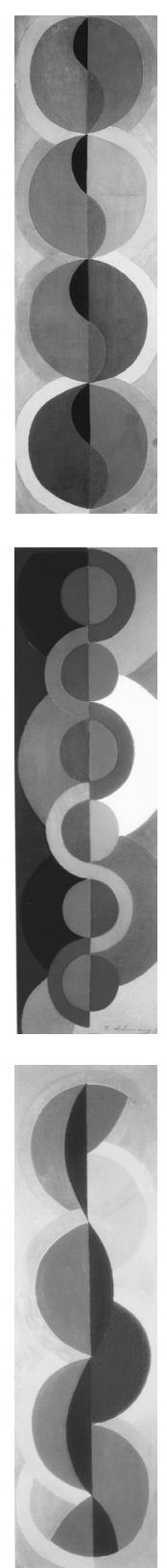
de pesos que se compensan. La enfermedad es vacuo exceso. La misión del arte curativo es conservar la salud en equilibrio, dejar que siga la vida como "un proceso de derroche" (1) orientado a su preservación. Desde la perspectiva de lo que para Gadamer es la salud y la enfermedad, la medicina constituye todo un arte de curar. En efecto, "La esencia del arte de curar consiste, más bien, en poder volver a producir lo que ya ha sido producido (1)". Se trata entonces, simplemente, de procurar restablecer el curso natural perturbado y hacer que el paciente se reencuentre con la liviandad del equilibrio oculto. En tal sentido, curar para Gadamer tiene funciones político-sociales, pues no es otra casa que reincorporar a los enfermos a la vida comunitaria.

Sin duda, esta ontología de la salud y de la enfermedad lleva a que Gadamer proponga que la medicina trascienda las prácticas positivistas de intervención y se mueva hacia un enfoque sistémico. Desde esa perspectiva, para el autor el médico no ha de limitarse a cuantificar (sintomatología) y aplicar unos fármacos, sino que se debe enfocar en el organismo como un sistema, no solo fisiológico, sino, lo que es más importante, un organismo con vida comunitaria. Cada organismo es uno y único. Por tal razón, según Gadamer, las prácticas generalizadas de la curación han degenerado el arte curativo. La confianza en quien cura no depende de que apele u ostente su autoridad, sino de que la demuestre en la práctica. La curación, de acuerdo con el autor, es un arte que constituye una gran conversación, a fin de desocultar y traer de nuevo o recuperar el estado oculto de la salud.

La perspectiva de Gadamer es una importante ruptura óntica y epistémica de la salud y la medicina que trasciende los paradigmas clásicos de la medicina y su práctica. Se podría afirmar que la tesis del autor es la humanización de la medicina, considerando que quien cura no coarta la libertad, puesto que si crea dependencia tanto del médico como de los fármacos, no habrá restaurado el equilibrio, más bien habría mantenido la enfermedad. $\mathrm{Al}$ conocer a fondo a sus pacientes el buen médico también se conoce a sí mismo (autognosis).

\section{La práctica médica en la era de la tecnología}

Es indiscutible que la ciencia médica, por un lado, y el ideal metodológico por otro, han contribuido a desfigurar la relación médicopaciente, la cual definen en términos de un acto médico reducido a la acción de "curar" la enfermedad, y esto propicia que un tercer elemento se incorpore a esta relación: la técnica médica, un mediador para reducir la distancia entre el médico y el paciente.

No cabe duda de que al abandonar la clínica se modificó la relación médico-paciente con el tránsito del modelo médico hipocrático al modelo médico científico y hegemónico (2). En este último la participación del paciente es eminentemente pasiva, receptiva, en espera de que se le diga lo que se debe hacer para restaurar o conservar el estado de salud. Con la supeditación del juicio derivado de la práctica clínica al uso racional de la tecnología médica, el padecer del paciente fue desplazado del acto médico, lo cual propició que se desechara la vivencia de la enfermedad, tanto del enfermo como de su familia y del entorno social del mundo que comparten. Finalmente, se descalifica el saber práctico del paciente, saber que ha adquirido al estar-en-el-mundo.

Para Jaspers la oposición entre la tendencia médica de promover la ilusión tecnológica en el dominio de la enfermedad y la experiencia vital del paciente en la salud, sin duda manifiesta la tensión entre la capacidad técnica y científica adquirida por el médico y 
el saber práctico del paciente. Para el autor, la tecnología limita el deseo del paciente de realizarse como ser humano mediante la difícil tarea de asumir su existencia.

Jaspers deja ver que a pesar del desarrollo técnico-científico de la medicina, "el médico ve los límites de su poder. No puede eliminar la muerte, aun cuando hoy es capaz de prolongar la vida en una proporción jamás conocida" (2). Con esta afirmación Jaspers quiere hacer ver el hiato que existe entre la ciencia, la tecnología y la humanidad del paciente. La tecnociencia se transmite a través de la instrucción, mientras que la humanidad se expresa por medio de su manera de obrar, de hablar. La tecnociencia aumenta el conocimiento y su capacidad se hace más crítica y metódica. Por el contrario, la humanidad no admite planificación. El autor con toda esta reflexión pone de relieve que los requisitos técnicos en la medicina tienen como secuela la influencia ruinosa sobre la realidad de la idea del médico. De otro lado, el progreso científico tiene como secuela una medicina que si no observa sus límites estará violando la autonomía del paciente, en otras palabras, su propia humanidad.

Estos dos textos constituyen una importante y urgente reflexión de cara los actuales paradigmas de la medicina, de las organizaciones de salud y sus prácticas.

\section{Referencias bibliográficas}

1. Gadamer HG. El estado oculto de la salud. Barcelona: Gedisa; 2001.

2. Jaspers K. La práctica médica en la era de la tecnología. Barcelona: Gedisa; 2003. 